\title{
LA VIDA DE TRES MUJERES NICARAGÜENSES EN EL CAFETAL DE COSTA RICA (2008-2018): HISTORIAS CONTADAS DURANTE LOS REENCUENTROS DESPUÉS DE 10 AÑOS
}

\author{
THE LIFE OF THREE NICARAGUAN WOMEN ON A COFFEE FARM \\ IN COSTA RICA (2008-2018): WHAT THEY TALKED ABOUT DURING \\ OUR REUNIONS AFTER 10 YEARS
}

Aya Shiode

Recibido: 02/02/2019 - Aceptado: 18/03/2019

\begin{abstract}
Resumen
Este documento es un informe que trata sobre una parte de las entrevistas hechas a tres mujeres migrantes nicaragüenses en situación irregular acerca de su vida y los cambios vividos en el transcurso de diez años entre 2008 y 2018. Las entrevistas se realizaron en octubre y noviembre de 2018 en una de las principales zonas cafetaleras de Costa Rica, Turrialba. Las historias contadas por estas mujeres constataron la difícil realidad que las rodea, pero a la vez su valentía y resiliencia por una vida más digna y esperanzada.
\end{abstract}

Palabras clave: migración, mujer, Nicaragua, Costa Rica, café.

\begin{abstract}
This document reports a part of interviews conducted with three Nicaraguan migrant women in irregular situations, regarding their life and changes over the course of ten years between 2008 and 2018. The interviews were conducted during October and November 2018 on one of the main coffee cultivation areas in Costa Rica, Turrialba. The histories told by these three women show the difficult reality which surrounds them, but it also shows their courage and resilience in aiming for a dignified and hope-filled life.
\end{abstract}

Keywords: migration, women, Nicaragua, Costa Rica, coffee. 


\section{Introducción}

Este documento es un informe ${ }^{1}$ que trata sobre una parte de las entrevistas realizadas en octubre y noviembre de 2018 en una de las principales zonas cafetaleras de Costa Rica, Turrialba. Las informantes entrevistadas fueron tres mujeres nicaragüenses en situación irregular (Organización Internacional para las Migraciones, 42) que yo había conocido durante la cosecha del café en Turrialba en 2008 y que he vuelto a encontrar después de 10 años en el mismo lugar. ${ }^{2}$ Estas tres mujeres relataron su vida y los cambios vividos desde que nos conocimos en 2008 hasta que nos reencontramos en 2018. Estas entrevistas tenían como objetivo escuchar su historia personal y comparar su vida en la cosecha del café en Costa Rica de hace una década con la actual.

Antes de realizar este trabajo de campo en 2018, mi esperanza era volver a entrevistar a los mismos informantes quienes participaron en mi primera investigación hace 10 años. No obstante, sabiendo el estilo de vida laboral de constante movimiento de las personas migrantes, yo era consciente de que no iba a ser fácil y el darse o no la situación de reencontrarlos dependería de la suerte. Al comenzar el trabajo de campo, afortunadamente me reencontré con aproximadamente diez migrantes, de los cuales, entrevisté a tres mujeres por más de tres horas. En las entrevistas mantenidas que era más conversación que entrevistas, ellas contaron generosa y valientemente su propia historia y experiencia de cómo ha estado su vida entre 2008 y 2018.

Estas historias y experiencias vividas son muy personales, pero a la vez casos en común, ya que miles de mujeres nicaragüenses podrían estar viviendo situaciones similares en Costa Rica y Nicaragua. ${ }^{3}$ Por lo que creo que las palabras de estas mujeres nicaragüenses merecen la pena ser escuchadas como un elemento más para una mejor comprensión de estas en la cosecha del café en Costa Rica.

\section{Lugar y método de la investigación}

Figura 1

UNA PARTE DE AQUIARES

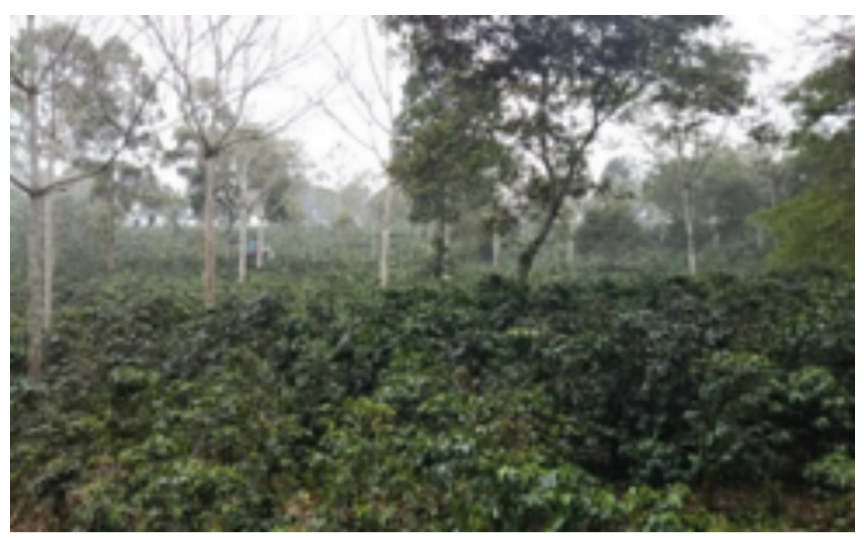

Fuente: Elaboración propia. 
El trabajo se realizó en los campamentos de la Cafetalera Aquiares S. A., ${ }^{4}$ la cual es la finca de café más grande que consta de solo una zona de cosecha en toda Costa Rica. Por su extensión geográfica y característica lluviosa, es una de las cafetaleras con más demanda de mano de obra durante el periodo más extendido a nivel nacional (Figura 1). La labor de recolectar café en Aquiares, igual que el resto de las fincas en Costa Rica se hace a mano. ${ }^{5}$ Por consiguiente, para las fincas de café en el país, incluyendo Aquiares, el tener suficiente número de trabajadores para la temporada de cosecha es de vital importancia. Aquiares contrata un poco más de 1000 trabajadores al día en su pico de cosecha.

Según el registro diario de la empresa acerca de la "entrada de cogedores" del 22 de noviembre de 2018, ${ }^{6}$ en un día pico de cosecha, un $13 \%$ de los trabajadores eran personas de Aquiares, un $44 \%$ viajaban a Aquiares desde los alrededores, y un $43 \%$ vivían temporalmente en los campamentos de la finca para trabajar, cuyos lugares son llamados comúnmente baches. Estos campamentos tienen capacidad para casi 500 adultos. Se paga a destajo, por lo que es difícil saber quién hizo cuántas cajuelas y cuánto ganó al día. Sin embargo, el promedio de las cajuelas hechas por trabajador en temporada pico de la cosecha en 2018 fue alrededor de 7 cajuelas, mientras para comienzos de la cosecha fue un poco menos de 2 cajuelas. En octubre y noviembre se pagaba entre 1200 y 1300 colones (USD 2.0 a 2.3) por cajuela.

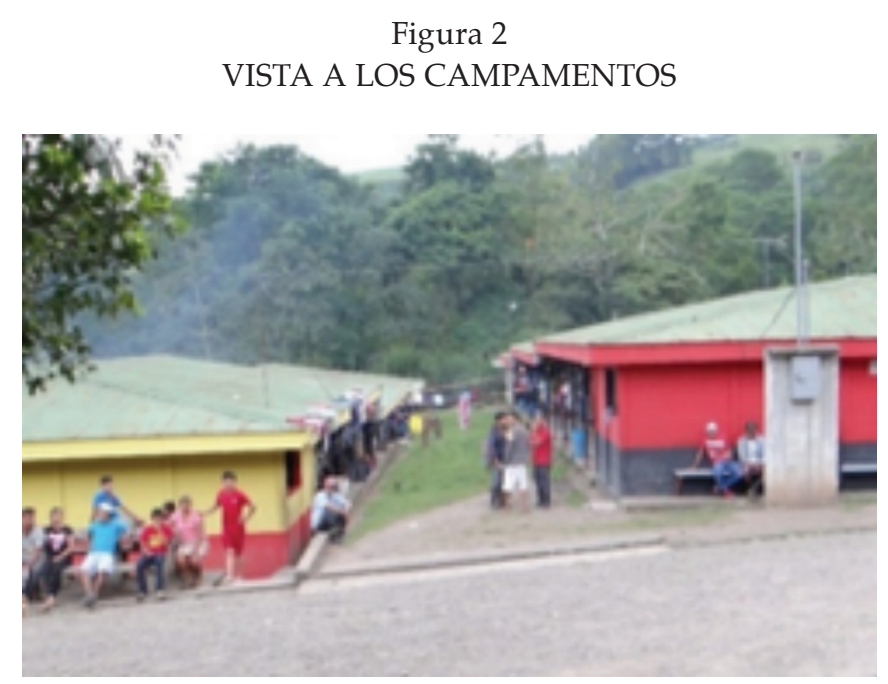

Fuente: Elaboración propia.

El trabajo de campo, igual que hace 10 años, lo realicé principalmente en los campamentos para recolectores, sitios que constituyen un lugar de convivencia de migrantes domésticos e internacionales, cuya mayoría son nicaragüenses. Comencé el 
trabajo ayudando a cuidar a los niños en la guardería. Antes de iniciar el trabajo de campo, ya había solicitado a la finca que me dejara estar en la guardería como primer paso, porque con la experiencia de hace 10 años, sabía que era el mejor lugar para encontrar o conocer a las mujeres recolectoras, que son madres. Llevaba siempre conmigo el álbum de fotografías de las personas que vivían en los campamentos en 2008 (Figura 2), con esperanza de poder encontrar o identificar a personas que aparecen en él. Como resultado y con mucha suerte, logré encontrar a diez personas, de las cuales, fue posible conversar y entrevistar a tres: Laura, Ana y Fernanda. Le expliqué a cada una de ellas mis motivos de la entrevista y deseos de escuchar cómo vivieron estos 10 años (2008-2018). Traté de que en la entrevista ellas pudieran hablar o contar lo que querían de manera voluntaria. Los nombres que aparecen en este informe son ficticios para proteger su privacidad, pero se utilizan los mismos nombres que aparecen en el informe del primer trabajo de campo en 2008 (Shiode, 2010) para así posibilitar la comparación de la situación con la de hace 10 años.

\section{Las historias orales de tres mujeres migrantes: su vida entre 2008 y 2018}

Un empleado de mantenimiento con más de 20 años de trabajar en los campamentos veía mi álbum de fotografías, me llamó y me llevó a donde estaba el camión lleno de recolectores que estaba a punto de salir para el campo (Figura 3). En el cajón del camión, estaban Laura y Ana. Así fue cómo me reencontré con ellas después de una década. Laura es la suegra de Ana, al igual que hace 10 años ahora andan y viven juntas.

Figura 3

A LAS 6 DE LA MAÑANA SALE EL ÚLTIMO CAMIÓN DE LOS CAMPAMENTOS HACIA EL CAMPO

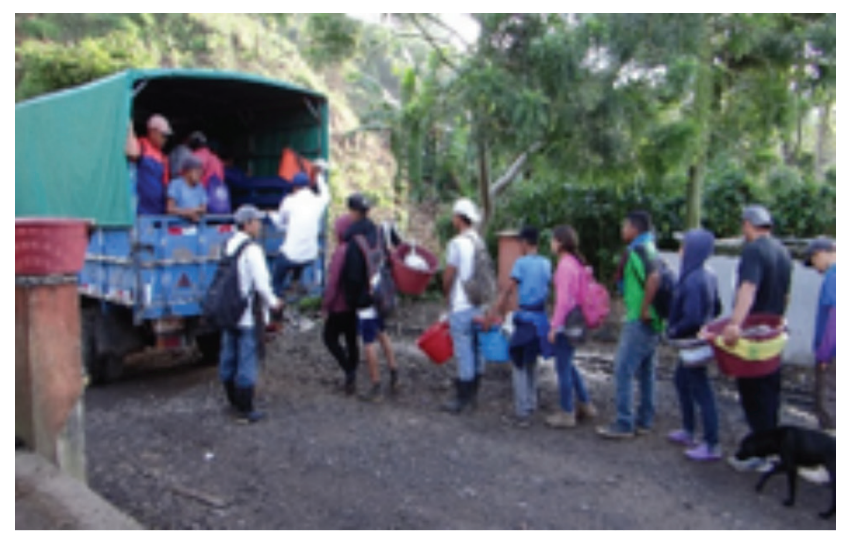

Fuente: Elaboración propia. 


\section{Caso de doña Laura}

Laura, oriunda de Granada, Nicaragua, de 46 años y una madre de dos hijas y un hijo, y todos con alrededor de 30 años, es migrante en situación irregular en Costa Rica. Cuando conocí a Laura hace 10 años por primera vez, ella convivía con su pareja costarricense, Carlos, de quien a los años se separó. Actualmente ella está con Tomás, costarricense también. En 2008 Laura trabajaba como ayudante en la fonda ${ }^{7}$ de los campamentos, en la que yo también ayudaba a cocinar. Le enseñé las fotos de ella y yo, preparando juntas comidas con leña. Al verlas, ella comenzó a hablar de su vida en estos 10 años. Los primeros 8 años en Costa Rica y los últimos 2 años en Nicaragua, hasta que volvió a migrar a Costa Rica en 2018.

Hasta hace 2 años, Laura trabajaba en distintos lugares de Costa Rica. Trabajó siempre en las siembras y cultivos de los productos agrícolas tales como café, caña de azúcar, zanahoria, papas y otros más. Los trabajos agrícolas dependen de la temporada, por lo que ella se trasladaba de un lugar a otro según la temporada laboral. Cuando le pregunté a Laura cómo tomaba la decisión sobre el destino, ella contestó que hay veces que vuelve a la finca que conoce, pero hay otras veces que busca nuevas fincas. Sobre cómo busca nuevas fincas o trabajo, ella comentó:

[Digamos que] nosotras somos compañeras. Entonces le dice a uno, "fijate que tal lado [la cogida o la finca] es buenísima" (...) que uno no conozca. [Entonces le pregunta:] "Podemos ir?" [La otra responde] "iSí! Vamos, vamos". Uno ya se viene a meter aquí. Así pasó (Laura, comunicación personal, octubre, 2018).

Laura ha ido a nuevas fincas, confiando en la información brindada por sus amigas. Sin embargo, hay riesgo de que esta información no sea acertada, independientemente de que la persona que da la información tenga o no buenas intenciones. En caso de volver a la finca que ya conoce, regresa creyendo que la finca continua en condiciones aceptables como antes. Si bien, aunque fueran favorables, no existe la garantía de que sigan siendo como en ese tiempo. Al respecto, Ana, nuera de Laura, contó su experiencia y la de Laura de haber regresado a una finca que conocían, pensando que la cogida de café sería buena y que la finca les daría beneficios como antes, pero llegando al lugar se dieron cuenta de que ya la cogida y los beneficios no eran buenos como sabían.

Para aminorar los riesgos, Laura explicó que hay veces que ella y su familia toman las siguientes medidas a la hora de pasarse a otro sitio: primeramente, un miembro de su familia o alguien de confianza, que suele ser un adulto masculino, va solo a la siguiente finca, con el fin de verificar si hay suficiente trabajo y disponibilidad de alojamiento para toda la familia. De parecerle bien la condición laboral y residencial, él lo avisa por teléfono al resto del grupo para que se traslade a la nueva finca. Laura recalca que la clave de esta medida preventiva está en que como primer paso solamente una persona vaya al lugar para la verificación, y que no todos se 
muevan de una vez precipitadamente antes de confirmar las condiciones, porque si todos se trasladaran y el estado de la finca incluyendo el trabajo y los alojamientos no fueran como se imaginaban, la familia se sumergirá en una situación gravísima. Esta explicación de Laura señala que ella y su familia vivían en constante traslado, asumiendo riesgos y costos precavidamente para buscar y encontrar trabajos en distintos lugares de Costa Rica durante todo el año, aunque no hay garantía de que el siguiente lugar sea aceptable y digno.

A las personas migrantes en situación irregular, no obstante, les esperan más retos, aun después de llegar a salvo a la siguiente finca y de ganar dinero como esperan ganar. Uno de ellos es la inexistencia de una medida segura para guardar su dinero. Laura no tenía una cuenta bancaria por no contar con los documentos necesarios para abrirla. Ante esta realidad, Laura contó su experiencia amarga y dura que le tocó vivir cuando terminó con su pareja, Carlos. Ella le pidió "prestada" la cuenta bancaria a él quien sí podía tenerla por ser costarricense, y en esa iba ahorrando el dinero de ella, de su hijo y Ana. Pero, al tiempo la relación de Laura y Carlos se complicó y ellos se separaron. Carlos, sin darles el dinero que les correspondía a los tres, desapareció y así Laura y su familia perdieron sus ahorros.

La moral de Carlos es indiscutiblemente inaceptable. Sin embargo, la historia de Laura describe la realidad cruel de la falta de un medio seguro para guardar los ingresos, en la que están las personas migrantes en situación irregular. Asimismo, Laura mencionó que la población migrante en situación irregular no puede acceder al sistema de seguro social, por lo cual no puede recibir el subsidio de incapacidad hasta obtener su pasaporte, en caso de que acontezca un accidente laboral, lo que con frecuencia ocurre en el trabajo de campo (Figura 4).

LOS RECOLECTORES DE LOS CAMPAMENTOS COSECHANDO CAFÉ EN AQUIARES

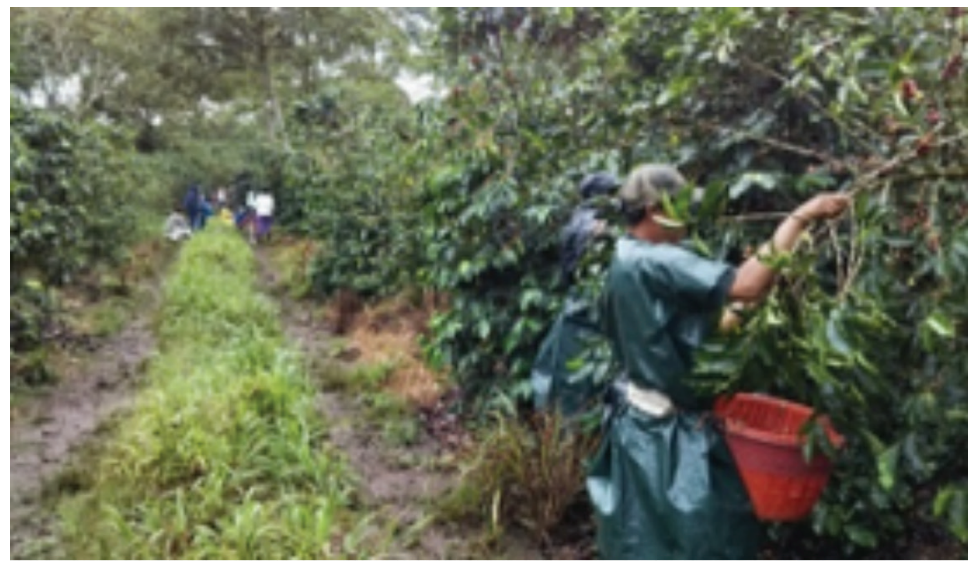

Fuente: Elaboración propia. 
Estas situaciones explicadas por Laura muestran que las personas migrantes en situación irregular viven sin recibir beneficios de los sistemas: el financiero (no tener manera segura para guardar sus bienes) y el de seguro social (no tener acceso a la protección ante la incapacidad por accidente laboral), aunque sí contribuyen a la economía formal de Costa Rica.

Los hechos ocurridos a Laura son pruebas de que las personas migrantes en situación irregular están en condiciones más severas que los de situación regular. Respecto a la vida de la población migrante en situación irregular, Laura dijo: "Las personas que andan sin papeles aquí nosotros somos muertos. No valemos nada". Ante estas palabras directas de Laura, me quedé impactada y no me quedaba otra que callarme por no encontrar palabras adecuadas para responderle. Es cierto que las leyes y declaraciones internacionales y universales garantizan la igualdad de todos los seres humanos: migrante o no, documentado o no. Pero, me preguntaba: ¿De qué sirve atreverme a decirle ahora a ella que "los derechos humanos son derechos inalienables de todos los seres humanos, dondequiera que se encuentren y cualquiera que sea su situación" (Oficina del Alto Comisionado de las Naciones Unidas para los Derechos Humanos, 10), a quien le ha tocado vivir experiencias crueles como estas simplemente por no contar con los documentos requeridos?

Laura es muy consciente de que la vida de las personas migrantes en situación irregular es mucho más dura que la de los documentados. Sin embargo, su historia revela que ella al menos tiene razones por las que no ha legalizado su estatus migratorio y anda "sin papeles" esta vez. La primera razón es el elevado costo para sacar papeles necesarios, en especial el pasaporte. Cuando le pregunté si tenía pasaporte, Laura contestó que no lo tenía, aunque dijo que "yo antes venía con pasaporte". Ahora anda sin pasaporte porque el sacar los documentos requeridos para la entrada oficial es costoso, por eso "mejor venimos por monte". Según Laura, un viaje legal de Granada a San José cuesta como mínimo unos USD 100 por persona, incluyendo el pasaporte, la visa y los boletos de bus de viaje redondo. En contraste, Laura dice que para este viaje "venimos con 1700 pesos de Nicaragua", lo que significa que el viaje "por monte" para dos personas adultas costó alrededor de USD 55. Un viaje de manera extraoficial les salió mucho menos de la mitad del viaje por vía oficial. Como se menciona posteriormente que, considerando la situación económica severa en la que estaba Laura antes de partir para Costa Rica en 2018, se entiende que a ella no le fue fácil preparar aun los USD 55. La segunda razón fue porque Laura siempre estaba con la idea de regresar a Nicaragua cuando la condición le permitiera, a pesar de que al final de cuentas resultó permanecer en Costa Rica durante 14 años y "siempre se ha quedado uno, viviendo sin papeles". Laura siempre tenía pensado regresar a Nicaragua por su terreno en Granada, por lo que no veía la importancia de legalizar su estatus. ${ }^{8}$ A Laura la hizo regresar y residir en Nicaragua hace 2 años el riesgo de que personas ajenas se metieran en su casa por dejarla vacía mucho tiempo por estar en Costa Rica. ${ }^{9}$ Ella trabajaba en Managua entre 
semana como empleada doméstica y durmiendo en el mismo lugar, cuidando a una señora mayor, de forma que solo pasaba los fines de semana en su casa en Granada. Este estilo de vida le permitió no tener que dejar su casa vacía por mucho tiempo. Aunque Laura no tenía ingresos muy altos, se conformaba con la vida en Nicaragua y no veía la necesidad de emigrar de nuevo a trabajar en Costa Rica.

No obstante, su entorno cambió en 2018, y en agosto migró de nuevo a Costa Rica después de 2 años de no haber estado en ese país. La principal razón por esta reemigración fue la pérdida del trabajo generada por la inestabilidad e inseguridad en Nicaragua. ${ }^{10}$ A Laura la despidieron del trabajo porque la señora a la que cuidaba se tuvo que mudar de Managua por la misma situación del país. Laura comenzó a buscar trabajo el 15 de mayo, último día del trabajo, asimismo esperaba que la situación social se calmara. Sin embargo, después de 2 meses no encontraba un nuevo trabajo ni veía que la situación se iba a estabilizar, lo que le hizo tomar la decisión de volver a emigrar a Costa Rica. Según Laura, para ella siempre existe la opción de emigrar cuando lo necesite:

Como ya uno conoce la pasada y la vida de aqui, entonces uno lo que hace es venirse para esta zona, Costa Rica. Uno dice: "Diay, no nos morimos de hambre, [porque] está la cogida de café". Así está ganando las bolsas de arroz (Laura, comunicación personal, octubre, 2018).

En cuanto al estado económico inminente en la que Laura se encontraba cuando decidió emigrar de nuevo en agosto, se puede saber a través de cómo ella reunió el dinero del viaje a Costa Rica, vendiendo a un precio bajo sus pertenencias. Laura cuenta:

Yo tenía una chanchita. Le digo yo a ella [Ana; nuera:] "la verdad de la cosa le digo yo... vender la chanchita e irnos para Costa Rica". Y, la regalada [vendí]. Ves, entonces en esa forma, porque no teníamos desembolso de nada. Lo único es sacar de lo que uno medio estaba haciendo (Laura, comunicación personal, octubre, 2018).

Con el dinero que le pagaron por la "chanchita", ella emigró con su hijo. Según lo que Laura contó, me dio a entender que la primera razón por emigrar de nuevo en 2018 fue la económica tras perder el trabajo. Pero había una razón más, la cual fue la seguridad de su hijo. Como su hijo es joven, Laura se angustiaba ante la posibilidad de que lo metieran en los pleitos sociales que aumentaban en el país. Laura comenta: "¿Por qué yo lo saco? Por lo que hay en Nicaragua. Porque está joven". Laura tenía que convencer a su hijo, quien no quería migrar por sus hijos, a que fueran juntos:

Él me dice: "mama, yo no me quiero ir... yo no quiero dejar a mis hijos solos...". Pero le digo yo: "por lo menos, vas allá a luchar algo a mandar a traerlos". Y, así pasó. (...) [Le decía:] "por lo 
menos allá hacemos algo y vamos a mandarles para que vengan ellos" (Laura, comunicación personal, octubre, 2018).

De lo que cuenta Laura, se nota que la madre y el hijo no migraron de nuevo porque querían, sino por la necesidad y la urgencia tanto de economía como de seguridad. Laura agrega diciendo:

Tantos años de no venir aquí, volver otra vez es como venir para sufrir, pues... Más que todo salimos como locos. Dejamos ahí.. No es que tenemos lindas cosas en Nicaragua, pero tenemos un rancho, una casita. [Pero dijimos:] "vámonos y ahí que queden esos" y nos venimos los dos. Ya después del tiempo, al tiempo ya mandamos a traer a ellos (Laura, comunicación personal, octubre, 2018).

Tras convencer a su hijo para que fueran juntos, Laura junto con su hijo con la limitada cantidad de dinero que podía preparar y unas cuantas ropas necesarias con que cambiarse al llegar a San José, cruzó "por monte". Caminaron horas, durmieron en un gallinero, madrugaron para tomar los diferentes buses que los llevarían a Aquiares vía San José y llegaron alrededor de las nueve de la noche al día siguiente desde su partida de su casa en Granada. Laura y su hijo, así comenzaron a trabajar nuevamente en Costa Rica, ahorraron dinero y lo mandaron a Nicaragua, así que a finales de septiembre (un mes y medio desde su llegada), Ana, su esposa y niños viajaron para reunirse con él y Laura en Aquiares.

\section{Caso de doña Ana}

Ana, esposa del hijo de Laura y de 31 años, es una madre de 3 niños: la primogénita (13 años), la segunda hija (10 años) y el hijo menor (7 años). Cuando conocí a Ana y a su segunda hija en 2008, la niña tenía menos de 1 año. Para este viaje a Costa Rica, Ana dejó a la hija mayor con su madre en Nicaragua. Ana, con los dos hijos más pequeños y nacidos en Costa Rica, nuevamente migró a este país después de 5 años. Los principales puntos de la historia de Ana sobre estos 10 años son dos: los prejuicios e incomprensión de la gente hacia las personas migrantes, y el dilema de querer ofrecerles buen ambiente a sus hijos, pero de que la difícil realidad no le ha permitido hacerlo. Ana no está convencida de que cuando un nicaragüense en Costa Rica comete un error, se les habla y se les ve a los nicaragüenses en general como si todos los nicaragüenses cometieran el mismo error. Asimismo, acerca de la percepción que las personas en Costa Rica tienen sobre la gente de los campamentos, Ana comenta:

Mire, hay algunos que vienen a hacer daño aquí [a Costa Rica]. Otros no. Por uno pagamos todos... Aqui a veces dicen que no vayan a los baches, porque hay gente mala, [pero] no todos somos malos... Hay gente que dice que los nicaragüenses piden, tal vez nosotros no. 
Son otros... Yo se lo dije una vez a un señor costarricense: ¿Por qué ustedes dicen que los nicaragüenses somos ladrones, somos malos, pues? [Le dije que] así somos nosotros, también son ustedes; unos son buenos, otros son malos (Ana, comunicación personal, octubre, 2018).

Ana se molesta porque en el país de destino se la juzga por su nacionalidad. Ella sabe que tanto nicaragüenses como costarricenses hay de todo y que no se puede generalizar por nacionalidad. Además de los sufrimientos por prejuicios en el lugar de destino, ella sufre también por la incomprensión de la gente en el lugar de origen sobre la vida de migrante. Ana, estando en Costa Rica, ha tenido días en los que no tiene qué comer, pero la gente en Nicaragua cree que los que emigraron a Costa Rica "se están dando una buena vida", lo cual está muy lejos de la realidad. Ana dice:

Es triste, triste, porque hay gente [en Nicaragua] que cree que uno viene aquí a Costa Rica con una buena vida, y [eso] no [es]. Aquí sufre bastante. Dicen: "Qué alegre que se va para Costa Rica", pero no saben que uno viene a sufrir aquí. Aguantar el hambre, aguantar el sol, aguantar lo que nunca ha aguantado allá en mi país (Ana, comunicación personal, octubre, 2018).

Además de los sufrimientos por los prejuicios y estereotipos sesgados tanto en el país de destino como de origen, otra relevancia de la historia de Ana circula sobre las situaciones y sentimientos en torno a los niños. Ana regresó de Costa Rica a Nicaragua hace 5 años y permaneció en Granada por sus hijos. En Costa Rica Ana vivía laborando en las siembras de distintos productos agrícolas, "arrancando culantro, zanahoria, remolacha... papas, repollos", además de café. Al corte de caña, solo su esposo iba a trabajar, aunque ella también "quería", porque según él ese trabajo "es de hombre". Respecto a los lugares que ha trabajado, Ana enumera que son Turrialba, Alajuela, Pérez Zeledón, San Marcos, San Ramón, Zarcero, Poco Sol en San Carlos, Corralillo, Cartago y otros más. De hecho, su hija nació en Grecia de la Provincia de Alajuela en 2008, y su hijo en Turrialba de la Provincia de Cartago en 2009: ambas zonas famosas por café. Ella, recordando el embarazo de su segunda hija, cuenta haber trabajado hasta el mismo día de que naciera, lo que muestra que Ana no solo vivió trabajando en distintos sitios del país, sino que también vivió los días de embarazo y parto, que a las mujeres les traen cambios drásticos física, psicológica y emocionalmente. Sin embargo, hace 5 años Ana tomó la decisión de regresar a Nicaragua para permanecer por el bien de sus niños nacidos en Costa Rica:

Como aquí [en Costa Rica] no tiene un lugar estable para estar: ando para acá y para allá, uno no puede andar con niños haciendo maletas para un lado y para otro lado. Y, de los estudios: 
no los puede estar cambiando dondequiera que vaya, por eso nos fuimos para allá para estar en un lugar estable que fueran estudiando ellos (Ana, comunicación personal, octubre, 2018).

Al regresar a Nicaragua, Ana trabajó "de lo que me fuera". Su último trabajo antes de volver a emigrar era el cuidado de una niña con necesidades especiales en Granada. La cuidaba desde las 6 de la mañana hasta las 10 de la noche. Sin embargo, los patrones de repente le bajaron su salario, y el salario después de la reducción no le alcanzaba para dar de comer a sus tres hijos, razón por la que no le quedaba otra que renunciar al trabajo. Al perderlo, la única forma de conseguir efectivo para darles de comer a sus niños era vender sus cosas. Ana comenta:

Yo tenía mis cositas de lo que yo trabajaba. Como ya no había trabajo ni nada, entonces vendi mis cosas; mis anillos, plata que tenía guardado y tanque de gas para cocinar también lo vendi porque no tenía nada que comer (Ana, comunicación personal, octubre, 2018).

Según Ana, cuando uno tiene un hijo "ya sabe de su responsabilidad de tocar de darle de comer", y su historia constata que ella les daba lo mejor que podía a sus hijos. De hecho, regresó a Nicaragua por lo mismo, para darles una vida más estable. Sin embargo, a pesar de sus esfuerzos, la reducción de su salario que ya no le alcanzaba para darles de comer, junto con la decisión tomada por su pareja y suegra por consecuencias ocurridas en el país, le hizo migrar de nuevo a Costa Rica.

Ana, al recibir el dinero que mandó su esposo de Costa Rica, viajó con sus dos hijos nacidos en Costa Rica a Aquiares de forma irregular, evitando las revisiones de documentos en los retenes fronterizos y asumiendo el cúmulo de riesgo y peligros en el camino. Ana dice "gracias a Dios pasamos bien [las revisiones de documentos de policías]”. Para Ana, quien logró reunificarse con su familia que había migrado un mes y medio antes, la preocupación actual es no poder ganar, ahorrar y enviar remesas a Nicaragua como había pensado (Figura 5). Ana dice que lo que está ganando apenas alcanza para comer "medio, medio", pero ella necesita ganar más urgentemente para poder mandarle a su hija que dejó en Nicaragua para su ceremonia de graduación de la escuela.

Uno viene aquí para recoger para mandarle porque se va a promocionar para el sexto, y uno tiene que mandarle dinero para el arreglo y cosas así que piden en la escuela. Y, ¿de dónde va a mandar si uno anda cogiendo [café] solo para comer? Entonces uno busca un poquito más de plata por otro lado (Ana, comunicación personal, octubre, 2018). 


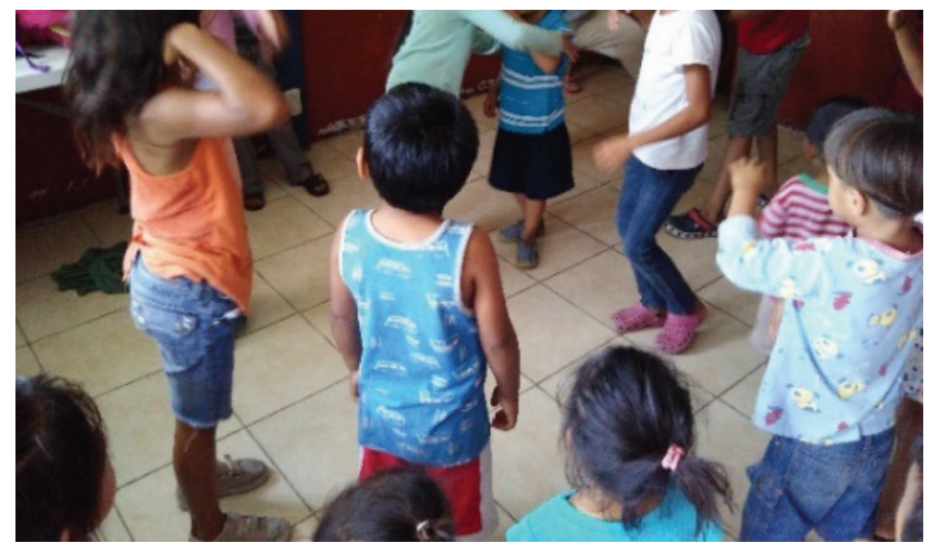

Fuente: Elaboración propia.

Ana actualmente no tiene ingresos suficientes para poder enviarle a su hija en Nicaragua. Ante esta situación, su pareja había buscado trabajo fuera de la finca en una granja para cuidar ganado. Los campamentos de esta cafetalera son exclusivamente para los recolectores de esta finca, por lo que su esposo al trabajar fuera de la finca no tiene derecho a estar en el sitio, aunque el resto de la familia trabaja para la cafetalera. Esta situación obligó a la familia de Ana y Laura a salir del lugar y mudarse a los campamentos de otra finca cercana, donde ya habían estado antes. Ana, quien regresó a Nicaragua para ofrecerles a sus hijos una vida más estable, a los 5 años, está otra vez viviendo en Costa Rica bajo un ambiente inestable y vulnerable tanto en el aspecto laboral como en el residencial.

\section{Caso de Fernanda}

Fernanda, nacida en Nicaragua y la segunda hija de seis hermanos, migró a Costa Rica junto con su madre y hermanos en 2007 cuando tenía 13 años, y que actualmente tiene 24 años. Cuando ella migró de Nicaragua a Costa Rica, estaba en el $5^{\circ}$ grado de la escuela. Mi primer encuentro con Fernanda fue cuando ella tenía 14 años y trabajaba como ayudante de cocina en la fonda de los campamentos (Laura y Fernanda trabajaban juntas). La he visto cinco veces en estos 10 años. Cada vez que la veía, siempre había avances en su vida: matrimonio, embarazos, partos y mudanza. Estos avances en su vida me daban una felicidad especial, porque la vida de Fernanda, quien no es una simple informante más, sino una amiga para mí, se encaminaba hacia una dirección positiva. Fernanda, trabajando en la fonda conoció a un joven costarricense, 
de quien se enamoró y se casó en 2011. Actualmente Fernanda vive feliz con su esposo y sus niños en una zona cercana a la finca. Sin embargo, después de 11 años de estar en Costa Rica, además de estar casada con un costarricense y ser madre de dos niños nacidos en el país, posee algunas dificultades por su estatus legal (Figura 6).

Figura 6

OCURREN CON FRECUENCIA SITUACIONES COMO LA DE FERNANDA, NO PODER IR A LA ESCUELA POR FALTA DE DOCUMENTOS

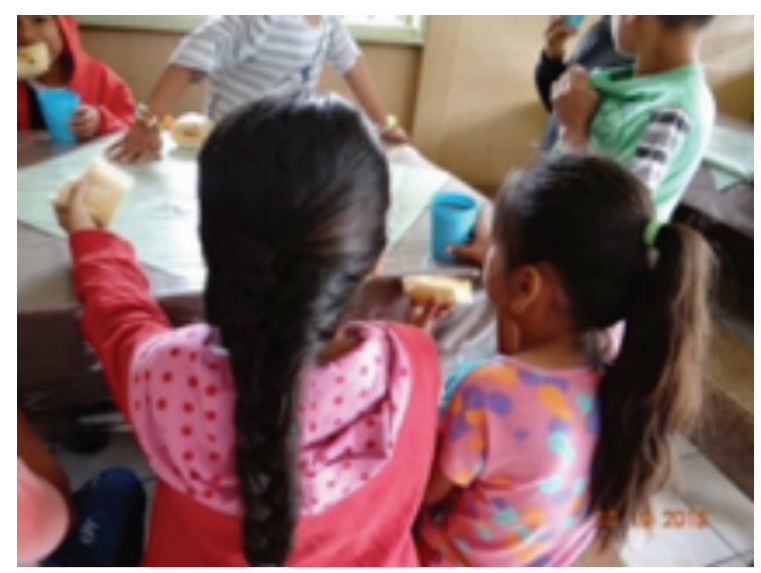

Fuente: Elaboración propia.

En Costa Rica los niños nacidos fuera del país también pueden recibir educación pública, pero Fernanda dice que "nunca he estudiado en Costa Rica por falta de documentos necesarios". Esta situación sucedió porque los padres de Fernanda no la registraron cuando nació, por lo que no contaba con partida de nacimiento $\mathrm{u}$ otro documento de identificación que se necesitaba para matricularse en la escuela. Fernanda, nacida en 1994, fue registrada finalmente por su madre alrededor del 2009 o 2010, porque le urgía el registro para poder casarse. Fernanda ya tenía 15 o 16 años cuando ella se quedó registrada oficialmente. A causa de haberse registrado con extrema tardanza, a Fernanda se le dificultó conseguir la cédula, y posteriormente el pasaporte, documento requerido para legalizar su estatus migratorio en Costa Rica. Fernanda a la fecha sigue siendo "migrante indocumentada" por no poder avanzar con los trámites migratorios. Su esposo trabaja en una fábrica, a través de lo cual ella, como esposa, podría acceder al seguro social. Sin embargo, por estar en estado irregular migratorio, ella no tiene acceso a los beneficios del sistema. Aunque su estatus legal irregular no le ocasionó ningún problema en los partos, ella hasta la fecha no puede recibir atención médica a menos de que sea de extrema gravedad, por lo tanto, 
nada de la atención preventiva. Además de no poder acceder a la atención médica, sigue sin recibir educación pública igual que hace 10 años.

Ocurren frecuentemente situaciones en las que las personas migrantes no pueden acceder a los servicios públicos por falta de documentos requeridos para los trámites, aunque sí, cumplen requisitos para solicitar. En efecto, tanto Laura como Ana y Fernanda cumplen requisitos para solicitar la residencia, ya sea por tener cónyuge costarricense o por tener hijo nacido en Costa Rica. No obstante, todas siguen como migrantes en situación irregular, lo que las hace estar en estado más vulnerable.

\section{Conclusión}

Un domingo de noviembre visité a Laura y Ana en su nuevo lugar de estadía después de Aquiares. Ana y su esposo no estaban en casa por haberse ido a trabajar, pero logré ver a Laura, su esposo y los dos niños de Ana. Ellos vivían en una vivienda sin luz para los trabajadores de la finca. Según contó Laura, su hijo y Ana trabajaban desde la madrugada hasta la noche los 7 días de la semana, con el fin de poder enviar remesas para la promoción de su hija a Nicaragua, ahorrar dinero para completar la construcción de su casa, comenzar un mini negocio y regresar a su pueblo, Granada, por la Semana Santa en 2019. Le pregunté a Laura cómo se siente con su vida actual en comparación con la de hace 10 años. Laura contestó tajantemente: "Yo veo que lo mío está más peor", pero a la vez dijo que "Mientras hay vida, hay esperanza, dicen. La vida de nosotros es salir adelante y trabajar". Por su parte, cuando Fernanda tenía 14 años, su sueño era "tener cancha de patinaje de hielo". Después de 10 años, la mujer de 24 años tiene sueño de ser bombera o estudiar en el Instituto Nacional de Aprendizaje (INA) para trabajar como chef o estilista de belleza. Además, quiere completar sus estudios de educación obligatoria, los cuales hasta ahora no ha podido por falta de documentos. Para cualquier avance que Fernanda quiera, se le requiere ordenar su estatus legal, para lo cual tiene planeado comenzar los trámites necesarios en diciembre, 2018.

Tras las entrevistas con las tres mujeres sobre sus 10 años, se pudo saber que cada mujer migrante ha buscado maneras para vivir de la mejor forma posible, reconociendo su estatus migratorio. Asimismo, se revelaron los problemas en común: situaciones en las que ellas se encuentran con vulnerabilidad, muchas veces producidos por falta de documentos y de dinero. Se necesita esfuerzo para que la gente pueda obtener documentos necesarios para una migración más segura y digna con esperanza.

\section{Notas}

1 La autora quiere agradecer al pueblo de Aquiares y la Cafetalera Aquiares, S.A., que desde hace 10 años le han abierto sus puertas para su investigación. Asimismo, les da un especial y profundo agradecimiento a las tres mujeres migrantes nicaragüenses: Doña Laura, Ana y Fernanda por dejarle escuchar sus historias muy personales. Muchas gracias también a Gloria 
Aidé Lomelí Zavala de la Universidad de Kansai Gaidai, Japón y Danny Orozco por su ayuda con la corrección del idioma español.

Para 2008, cuando yo comenzaba a estudiar la migración nicaragüense en Costa Rica como estudiante de maestría, ya había varias investigaciones académicas sobre este tema. $\mathrm{Mi}$ principal interés era la creciente migración laboral de Nicaragua a Costa Rica, comenzada principalmente en los 90, pero más específicamente la migración en la cosecha del café en Costa Rica, sobre la cual había algunos estudios hechos (Shiode, 2009). Sin embargo, con el deseo de indagar más y entender mejor a las mujeres nicaragüenses migrantes recolectoras de café a través de observaciones in situ, realicé trabajo de campo incluyendo entrevistas a ellas en la cafetalera Aquiares en Turrialba en 2008, cuyo resultado véase Shiode (2010). El trabajo de campo me dio a entender que era necesario tener miradas no solo del país de destino sino también del país de origen. Esta fue la razón por la que decidí ir a residir y trabajar en Nicaragua. El trabajar como investigadora para asuntos políticos y económicos de Nicaragua, asimismo el conocer esta nación como residente, me ayudaron a analizar el tema de la migración con una vista desde el lado nicaragüense, lo que me motivaba a entender más a las personas que conocí en la finca durante el trabajo de campo en 2008. Por ello, aprovechando las vacaciones laborales, yo visité Aquiares desde Nicaragua, y así trataba de mantener amistad con la gente y la finca. En 2017 volví de nuevo a Aquiares para saber si a la finca seguían llegando los nicaragüenses y si fuera posible realizar otro trabajo de campo al año siguiente. En 2018 desde Japón escuchando las noticias sobre la inestabilidad en Nicaragua y la salida de miles de nicaragüenses al exterior, en especial a Costa Rica, seguí con el plan original de mi segundo trabajo de campo en Aquiares, 10 años después del primero.

Costa Rica necesita alrededor de 76 mil recolectores de café, de los cuales un $40 \%$ : es decir más de 30 mil, son nicaragüenses (Cerdas).

La Cafetalera Aquiares tiene un significado especial para los países que están lejos de Costa Rica también. Es una cafetalera con reconocimiento nacional e internacional, exportando hacia Estados Unidos, Europa y Asia incluyendo Japón. La parte de siembra de café es de 675 hectáreas.

"Se utiliza el método de recolección manual y selectivo: solo se escoge el grano maduro (en óptimos de maduración); esto permite un mejor lavado del café" (Instituto del Café de Costa Rica).

Esta información fue brindada por el Señor Manuel Jara, gerente agrícola de la empresa durante la entrevista mantenida el 22 de noviembre de 2018 en su oficina.

Las fondas son comedores o sodas para los trabajadores y sus familias en los campamentos. La fonda en los campamentos en Aquiares funciona como pulpería (tienda de abarrotes) también.

De hecho, cuando Laura se regresó a Nicaragua, Tomás fue quien viajó a Nicaragua para vivir juntos.

Laura, por haber dejado su casa vacía por mucho tiempo por estar en Costa Rica, alguien intentó ocuparla. Para recuperarla, tuvo que llevar el caso a juicio.

La inestabilidad e inseguridad comenzadas en abril de 2018 en protesta del gobierno del presidente Daniel Ortega se han extendido durante el resto del año, en el cual cientos de personas, incluyendo jóvenes, han sido asesinadas, además de ser amenazadas, detenidas, secuestradas o torturadas. 


\section{Bibliografía}

Cerdas,D. “30.000familias todavíasegananelsustentoencogidas decafé". LaNación, 18 de diciembre de 2016. Recuperado de https://www.nacion.com/el-pais/30-000-familias-todavia-se-ganan-el-sustento-en-cogidas-de-cafe/WNJ3BIOEXRC4FN3GNGDFWFR5SU/ story/

Naciones Unidas. Los derechos económicos, sociales y culturales de los migrantes en situación irregular, 2014. Recuperado de https://www.ohchr.org/Documents/Publications/ HR-PUB-14-1_sp.pdf

Instituto del Café de Costa Rica. El mejor café del mundo. Recuperado de http://www.icafe.cr/ nuestro-cafe/el-mejor-cafe-del-mundo

Organización Internacional para las Migraciones. N7 Glosario sobre Migración, 2006. https:// publications.iom.int/system/files/pdf/iml_7_sp.pdf

Shiode, Aya. A Field Work Report on Nicaraguan Working Female Migrants on a Coffee Farm in Eastern Costa Rica. The Bulletin of Global Human Studies (2010): 119-132.

Shiode, Aya. Nicaraguan migrants in Costa Rica: case of working women in coffee farms. The Bulletin of Global Human Studies (2009): 73-81.

Aya Shiode. Japonesa, obtuvo su licenciatura en Lingüística y Cultura con especialidad en Estudios Latinoamericanos y el idioma español y maestría en Ciencias Humanas ambas por la Universidad de Osaka, Japón. Se desempeñó como Investigadora/Asesora de la Embajada del Japón en Nicaragua. Ha publicado artículos A field work report on Nicaraguan migrant working women in the eastern coffee farm in Costa Rica (2010), y Nicaraguan migrants in Costa Rica: case of working women in coffee farms (2009), ambos publicados en Osaka University Human Sciences Bulletin y escritos en japonés.

Contacto: shiodeaya52@gmail.com

ORCID: 0000-0002-5129-8834 